\title{
Comparative Analysis of Plasma Antenna with Metal Antenna
}

\author{
Abdul Samad \\ UET Peshawar
}

\author{
Kashif Azim, PhD \\ ICT, Islamabad
}

\author{
Shahzada Alamgir Khan, \\ PhD \\ ICT, Islamabad
}

\begin{abstract}
This paper is designed to prove that Monopole Plasma Antenna is better than that of traditional Metal Antenna in terms of bandwidth, directivity, gain, radiation efficiency, VSWR and return losses.Mathematical model (Drude Lorentz Model) of plasma antenna and traditional metal antennas are analyzed at two different resonant frequencies of $1 \mathrm{GHz}$ and $2.4 \mathrm{GHz}$ by using the simulation software Computer Simulation Technology CST-Microwave Studio Suit 2010 which is commercially available. Several parametric analyses have been performed to analyze bandwidth, directivity, higher gain, radiation efficiency, and VSWR and insertion losses of both the Plasma and Metal monopole antenna.After delicate analysis, it is found that monopole plasma antenna is much better than that of traditional monopole metal antenna in terms of their parameters including bandwidth, directivity, higher gain, radiation efficiency, and VSWR and insertion losses.
\end{abstract}

\section{Keywords}

Bandwidth, Directivity, Gain, Radiation Efficiency, VSWR and Insertion Losses.

\section{INTRODUCTION}

\subsection{Basic Antenna}

Antennas can be designed to transmit and receive radio waves either in all horizontal directions equally (Omni directional antennas) or preferentially in a particular direction (Directional or high gain antennas) [1]. Traditional metallic antenna consists of metallic conductors, electrically connected (often through a transmission line) to the receiver or transmitter. An oscillating current creates an oscillating magnetic field around the antenna elements. These time varying fields radiate away from the antenna into space as a moving transverse electromagnetic wave. Conversely, during reception, the oscillating electric and magnetic fields of an incoming radio wave exert force on the electrons in the antenna elements causing them to move back and forth, creating oscillating currents in the antenna.

Antennas are characterized by a number of performance measures which a user would be concerned with in selecting or designing an antenna for a particular application. Two major factors associated with the design of antennas are the antenna resonant point or center operating frequency and the antenna bandwidth or the frequency range over which the antenna operates. Other parameters are gain, directivity, radiation efficiency, return loss and VSWR [2].

\subsection{Plasma Antenna}

Unlike traditional metal antenna, plasma antenna is based on partially or fully ionized gas used as a conducting material [3]. A plasma antenna is made up of column of ionized gases in which free electrons emit, reflect and absorb the radio signals as free electrons in a metal antenna. Argon, Krypton and Xenon gases are used in Plasma tube because these are chemically inert and don't attack the Plasma tube and electrodes. Plasma antenna can be energized by any of nonthermal generation techniques [4].Main advantage of plasma antenna is that they are highly reconfigurable antennas as ionized gas can be easily switched ON and OFF at any time interval to make a phase shift in an array [5]. This feature makes it suitable to perform beam steering in very short time (millisecond) and provide degrees freedom at wider range of beam steering angle covering the 0 to $360 \mathrm{deg}$ span.

\section{FEATURES OF PLASMA ANTENNA}

Gas ionization process of the plasma antenna is resistance control which is the fundamental feature of the plasma antenna. Whenever the plasma column is de-ionized then gas has large resistance which tends to infinite and does not interact with RF radiations [4]. In this condition, antenna doesn't backscatter the radar waves and provides stealth. This feature makes the plasma antenna possible to use in an impulse radar and high-speed digital communications.

Plasma antenna technology has the additional features which are mentioned hereunder that shows future growth of plasma technology:

- As plasma antenna is non-metallic, it provides stealth by reducing Reduced Radar Cross Section (RCS).

- Plasma antenna has no noise floor (virtually) when gas inside the plasma is ionized.

- De-coupling from nearby high-frequency transmitter is possible even with low ionization level of plasma antenna during operation state.

- A circular scan (up to span of $360^{\circ}$ ) can be performed electronically with no moving parts at a much higher speed than traditional mechanical antenna structures.

- Plasma antenna can be made appear and disappear in milliseconds to steer the beam at required direction and angles.

- Plasma antenna has less thermal noise than in metal antennas.

\section{APPLICATIONS OF PLASMA ANTENNA}

Plasma antenna has been used extensively in a wider range of applications mentioned below:

- In high-speed digital communication and radar system.

- In radio antenna.

- Stealth for military application.

- Used for transmission and modulation techniques (PM, AM, FM). 
Plasma antenna has been used in military applications which are as follows [6]:

- Shipboard/submarine antenna replacements.

- Unmanned air vehicle sensor antennas.

- Land-based vehicle antennas.

- Stealth aircraft antenna replacements.

Plasma antenna has also been targeted for commercial applications mentioned below:

- Telemetry \& broad-band communications.

- Ground penetrating radar Navigation

- Weather radar and wind shear detection.

- Collision avoidance

\section{COMPARISON BETWEEN PLASMA AND METAL MONOPOLE ANTENNA}

According to literature review, following parameters of plasma antennas are compared with that of metal antenna [7],

\subsection{High Power}

Due to low ohmic losses, high power may be achieved from plasma antenna as compare to metal antenna. Power capabilities in wider range are available in Plasma antenna than that of metal antenna. Princeton University experimental fusion reactors performed the experiments in fluorescent bulbs and convert the plasma low power to extremely high-power [6]. As plasma does not melt so the plasma antenna may be protected from fire resistance and heat. Because of high power and directivity, plasma antenna can enhance target discrimination and track ballistic missiles at the $\mathrm{S}$ and $\mathrm{X}$ band.

\subsection{Enhanced Bandwidth}

Density of plasma can be controlled by using LASER and Electrodes. Consequently, controlled density of plasma in space and time suggested that higher bandwidth of the plasma antenna can be obtained than that of metal antenna of the same geometry. Improved discrimination can be achieved with this improved bandwidth.

\subsection{EMI/ECI}

EMI/ECI effect eliminates for incoming electromagnetic signals when the plasma antenna either turned-off or in the low density region thereby producing stealth. Several plasma antennas are electron densities adjusted so that one antenna invisible to others during operation. Physically, mutual side lobe and back lobe clutter is highly reduced and hence jammed.

\subsection{High Efficiency and Gain}

As the Ohmic losses of plasma antenna are lower hence the radiation efficiency of plasma antenna is higher. Phase conjugate matching with the feeds of antenna can be achieved by adjusting of plasma density and can be maintained during reconfiguration that may cause higher standing wave efficiency. $20 \mathrm{~dB}$ improvements in antenna efficiency are estimated during experiments.

\subsection{Reconfiguration and Multi- functionality}

The plasma antenna can be made reconfigure on fly by controlling variation of the plasma density in space and time as compare to metal antennas. Consequently, no. of elements, size and weight can be reduced of shipboard antennas. One option is to construct controlled density plasma blankets around the Plasma antennas thereby creating windows (low-density sections of the blanket) for main lobe transmission or reception and closing windows (high-density regions in the plasma blanket) [10]. The Plasma windowing effect (low-density sections of the blanket and high-density regions in the plasma blanket) increases gain and directivity. Closing Plasma window (high-density regions in the plasma blanket), where back lobes and side lobes exist, eliminates them and reduces clutter and jamming. $40 \mathrm{~dB}$ enhancements may be achieved in directivity and discrimination by reducing these side lobes.

\subsection{Low Noise}

The Plasma antenna has a lower Collision rate among charge carriers of plasma antenna is very low as compare to metal antenna that may cause of less noise.

\subsection{Perfect Reflector}

Plasma is a perfect reflector if the plasma density is very high. Hence possibilities exist for wide range of lightweight Plasma.

\section{DESIGN AND SIMULATION RESULT \\ Monopole Plasma Antenna}

A unit element of quarter-wave monopole Plasma antenna is designed in CST-Microwave Studio Suit 2010 as shown in Figure-1. Plasma antenna has been designed at resonant frequencies of $1 \mathrm{GHz}$ and $2.4 \mathrm{GHz}$ respectively [8]. Keeping in mind the dispersion of particles inside Plasma, the Drude model is considered for dispersion model [9].

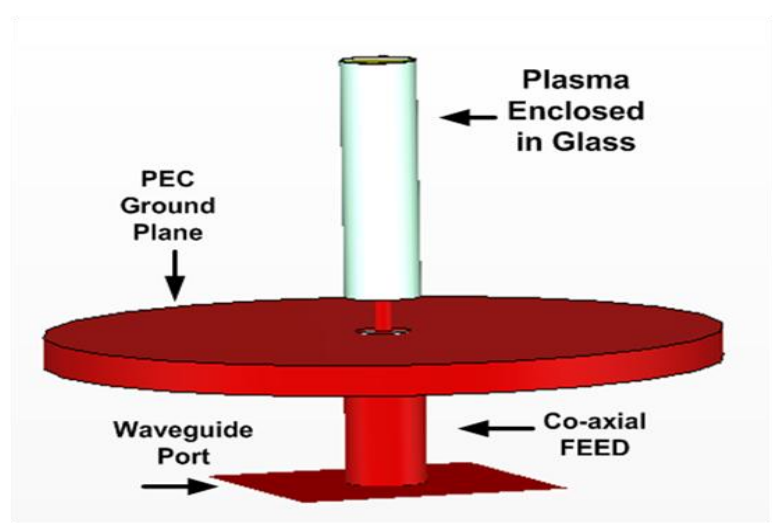

Fig 1: Unit element of Plasma Antenna-Front side

\subsection{Band Width Comparison}

An antenna's bandwidth specifies the range of frequencies over which its performance does not suffer due to a poor impedance matching. Normally it is the frequency band over which the magnitude of Reflection Coefficient is below -10 $\mathrm{dB}$ or magnitude of return loss is greater than $10 \mathrm{~dB}$ or VSWR is less than approximately ' 2 ' $[11,12]$. 


\subsubsection{Plasma and Metal Monopole Antennas at resonant frequency of $2.4 \mathrm{GHz}$}

Impedance Bandwidth at resonant frequency of $2.4 \mathrm{GHz}$ by using monopole plasma antenna and Metal Antenna can be calculated in Figure-2. According to the Figure-2, Straight graph shows the Impedance Bandwidth calculation of Plasma Antenna while the dotted graph shows the Impedance Bandwidth at $2.4 \mathrm{GHz}$. In both the graphs, we observe the Reflection Coefficient of less than $-10 \mathrm{~dB}$ over the frequency band to obtain higher and lower frequencies. In case of Plasma Antenna, fractional bandwidth is (2569.4 2217) $/ 2400=0.146 \times 100=14.6 \%$ at $2.4 \mathrm{GHz}$ and in case of monopole metal antenna, the fractional bandwidth is $(2535.5$ - 2277.7) / $2400=0.1074 \mathrm{X} 100=10.74 \%$ at 2.4 $\mathrm{GHz}$. The return loss of Plasma Antenna is as low as $-34 \mathrm{~dB}$ while for Metal Antenna is $-15 \mathrm{~dB}$.

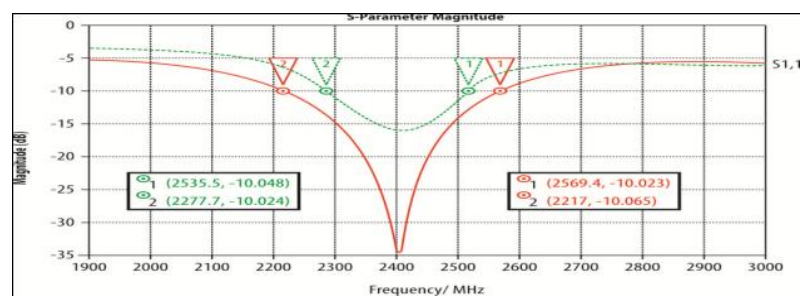

Fig 2: Impedance Bandwidth at $2.4 \mathrm{GHz}$

\subsubsection{Plasma and Metal Monopole Antennas at resonant frequency of $1 \mathrm{GHz}$}

A unit element of Monopole Plasma Antenna and Metal Antenna is also designed at resonant frequency of $1 \mathrm{GHz}$. In Figure-3, Straight graph depicts the Impedance Bandwidth calculation of Plasma Antenna while the dotted graph depicts the Impedance Bandwidth at $1 \mathrm{GHz}$. By visualizing the graph, higher and lower frequencies are taken at $-10 \mathrm{~dB}$. In case of Plasma Antenna, fractional bandwidth is $(1199.2-857.95) / 1000=0.3413 \times 100=34.13 \%$ at $1 \mathrm{GHz}$ and in case of monopole metal antenna, the fractional bandwidth is $(1165-916) / 1000=0.249 \times 100=24.9 \%$ at $2.4 \mathrm{GHz}$. The return loss of Plasma Antenna is as low as -32 $\mathrm{dB}$ while for Metal Antenna is $-16 \mathrm{~dB}$.

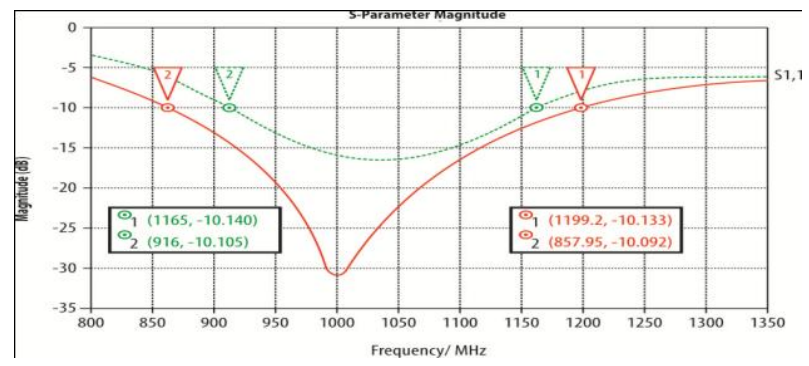

Fig 3: Impedance Bandwidth at $1 \mathrm{GHz}$

Table 1. Bandwidth comparison

\begin{tabular}{|c|c|c|c|c|}
\hline Parameter & \multicolumn{2}{|c|}{ Plasma Antenna } & \multicolumn{2}{c|}{ Metal Antenna } \\
\hline $\begin{array}{c}\text { Resonant } \\
\text { Frequency }\end{array}$ & $\begin{array}{c}\text { Fractional } \\
\text { BW (\%) }\end{array}$ & $\begin{array}{c}\text { Return } \\
\text { Loss } \\
\text { (dB) }\end{array}$ & $\begin{array}{c}\text { Fractional } \\
\text { BW (\%) }\end{array}$ & $\begin{array}{c}\text { Return } \\
\text { Loss } \\
\text { (dB) }\end{array}$ \\
\hline $\mathbf{2 . 4} \mathbf{~ G H z}$ & 14.6 & -34 & 10.74 & -15 \\
\hline $\mathbf{1 ~ G H z}$ & 34.13 & -32 & 24.9 & -16 \\
\hline
\end{tabular}

\subsection{Directivity Comparison}

Directivity is the ability of an antenna to focus energy in a particular direction when transmitting or to receive energy better from a particular direction when receiving.

\subsubsection{Plasma and Metal Monopole Antennas at resonant frequency of $1 \mathrm{GHz}$}

For measuring far field parameters, three different frequencies i.e. $900 \mathrm{MHz}, 1000 \mathrm{MHz}$ and $1100 \mathrm{MHz}$ are being used at resonant frequency of $1 \mathrm{GHz}$. After simulation, the results can be seen from Figures- $4 \& 5$. In case of Plasma Antenna (Figures 4), directivity is $2.06 \mathrm{dBi}$ and radiation efficiency of $4.553 \mathrm{~dB}$ while in case of metal antenna (Figures 5), directivity is almost $1.32 \mathrm{dBi}$ with very low radiation efficiency of $1.075 \mathrm{dBi}$. These results show that plasma antenna has improved directivity with better radiation efficiency as compared to metal antenna with same dimensions and properties. By analyzing the results, it has been proved that plasma antenna is more directive and radiation efficient than that of traditional metal antenna.

Similarly, $3 \mathrm{~dB}$ angular width (Beam width) of plasma antenna is $80.1 \mathrm{deg}$ which is more than traditional metal antenna (68.9 deg) as shown in Figure $4 \& 5$.

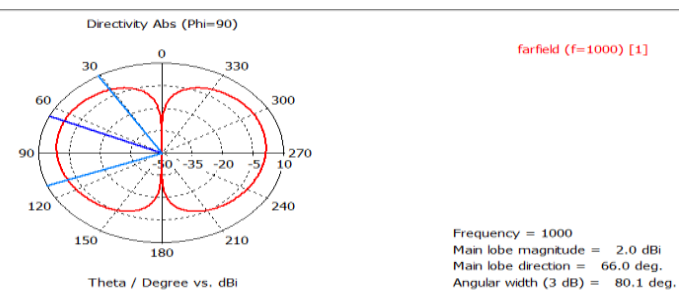

Fig 4: Radiation Pattern of Plasma Antenna at $1 \mathrm{GHz}$
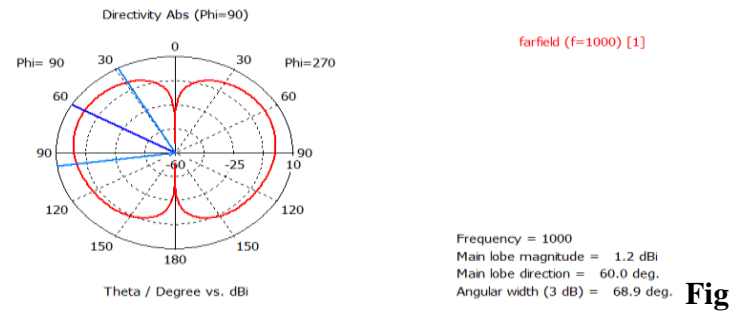

5: Radiation Pattern of Metal Antenna at $1 \mathrm{GHz}$

Table 2. Directivity comparison at $1 \mathrm{GHz}$

\begin{tabular}{|c|c|c|}
\hline Parameter & Plasma Antenna & Metal Antenna \\
\hline Freq. (MHz) & Directivity (dBi) & Directivity (dBi) \\
\hline $\mathbf{9 0 0}$ & 1.75 & 1.347 \\
\hline $\mathbf{1 0 0 0}$ & 2.02 & 1.316 \\
\hline $\mathbf{1 1 0 0}$ & 2.4 & 0.689 \\
\hline
\end{tabular}

5.2.2 Plasma and Metal Monopole Antennas at resonant frequency of $2.4 \mathrm{GHz}$

A unit element of monopole plasma antenna and metal antenna is also designed at resonant frequency of $2.4 \mathrm{GHz}$. The far field monitors are placed at $2.2 \mathrm{GHz}, 2.4 \mathrm{GHz}$ and $2.6 \mathrm{GHz}$ respectively. It can be seen from Figure- 6 that the maximum directivity achieved for monopole plasma antenna is $5.4 \mathrm{dBi}$ with side lobe levels as low as $-14.1 \mathrm{~dB}$. The green line in Figure-6 shows the radiation pattern of an isotropic antenna while the red line shows the radiation pattern followed by monopole plasma antenna at resonant frequency of $2.4 \mathrm{GHz}$. The minimum value of side lobes made it almost following the trend of isotropic antenna. 


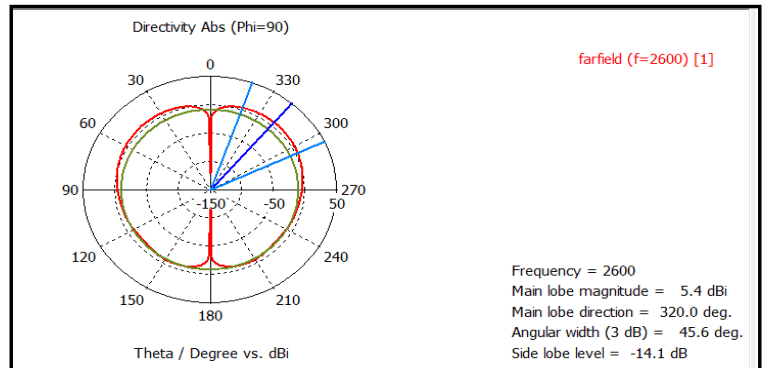

Fig 6: Radiation Pattern of Plasma Antenna at $2.4 \mathrm{GHz}$

Table 3. Directivity comparison at $2.4 \mathrm{GHz}$

\begin{tabular}{|c|c|c|}
\hline Parameter & Plasma Antenna & Metal Antenna \\
\hline Freq. (MHz) & Directivity (dBi) & Directivity (dBi) \\
\hline $\mathbf{2 2 0 0}$ & 3.4 & 3.2 \\
\hline $\mathbf{2 4 0 0}$ & 4 & 3.8 \\
\hline $\mathbf{2 6 0 0}$ & 5.4 & 4.3 \\
\hline
\end{tabular}

\subsection{Gain Comparison}

Antenna gain or power gain may be defined as, 'the ratio of radiation intensity in a given direction to the radiation intensity of an antenna radiated isotropic manners'. Gain is a dimension-less factor related to power and expressed in decibels.The higher value of radiation efficiency of monopole plasma antenna made it possible to produce enhanced values of gain which are much higher than that of traditional metal antenna. Antenna Gain plot is also available at CST Microwave studio.Comparison of Gain between Plasma Antenna and Metal Monopole Antenna at $2.4 \mathrm{GHz}$ and $1 \mathrm{GHz}$ is shown in following Table-4 and Table-5 respectively.

Table 4. Gain comparison at $2.4 \mathrm{GHz}$

\begin{tabular}{|c|c|c|}
\hline Parameter & Plasma Antenna & Metal Antenna \\
\hline Freq. (MHz) & Gain (dB) & Gain (dB) \\
\hline $\mathbf{2 2 0 0}$ & 2.9 & 2.6 \\
\hline $\mathbf{2 4 0 0}$ & 3.5 & 3.1 \\
\hline $\mathbf{2 6 0 0}$ & 5 & 3.6 \\
\hline
\end{tabular}

Table 5. Gain comparison at $1 \mathrm{GHz}$

\begin{tabular}{|c|c|c|}
\hline Parameter & Plasma Antenna & Metal Antenna \\
\hline Freq. (MHz) & Gain (dB) & Gain (dB) \\
\hline 900 & 6.035 & 3.72 \\
\hline 1000 & 6.613 & 3.191 \\
\hline 1100 & 7.398 & 2.606 \\
\hline
\end{tabular}

\subsection{VSWR Comparison}

Voltage Standing Wave Ratio (VSWR) is a measure of numerical description of how much the antenna is matched to transmission line connected to it. It is the ratio between peak amplitude and minimum amplitude of a standing wave along a transmission line.

SWR of 1:1 is ideal. SWR of 1.5:1 is considered acceptable in low power applications where power loss is more critical. Minimizing impedance differences at each interface (impedance matching) will reduce SWR and maximize power transfer through antenna system.

It can be seen in Figure-7, the value of VSWR of Plasma antenna (straight graph) is $\mathbf{1 . 0 3 9 7}$ at resonant frequency of $2.4 \mathrm{GHz}$ which is much closer value to the matched VSWR which is 1 while VSWR of monopole Metal antenna (dotted graph) is 1.3898 at resonant frequency of $2.4 \mathrm{GHz}$ which is far away from 1 the matched value of VSWR.

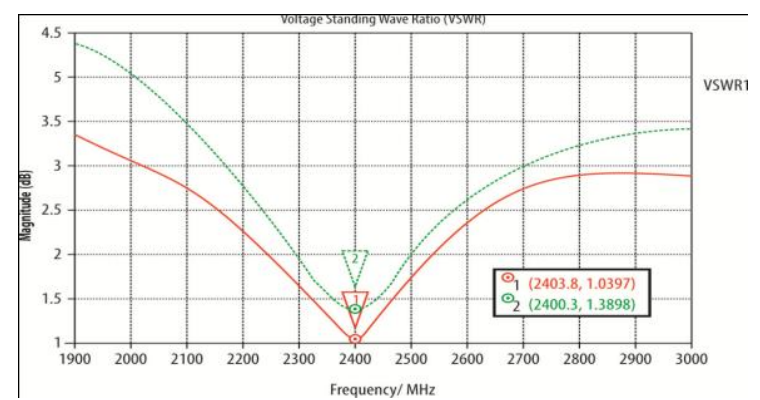

Fig 7: VSWR plots of Plasma \& Metal Antenna at 2.4 GHz

This shows that monopole plasma antenna has less losses and reflections and is perfectly matched with the transmission line which leads to be matched value of VSWR for plasma antenna.

\section{PARAMETRIC STUDY OF PLASMA ANTENNA}

Performance of proposed Plasma antenna can be improved by varying different geometries and parameters of Plasma Antenna including,

- $\quad$ Varying the radius of monopole antenna.

- Varying the dielectric constant of glass in which plasma is enclosed.

- Varying the thickness of glass.

- Varying the Length of monopole antenna.

- A gap is created in between of ground plan and feeding point of plasma antenna, so the gap is varied at range of values.

- Varying the length of feeding co-axial cable.

- Varying the dielectric constant of substrate used in co-axial feeding cable.

Some important parameters that may improve the bandwidth are discussed and simulated in this project and shown the results hereunder.

\subsection{Varying gap ' $g$ ' between Plasma Column and Ground plane}

The parametric study has been done by varying gap $(\mathrm{g})$ in between of plasma column and ground plane as shown in Figure-8. Increasing the gap ' $\mathrm{g}$ ' decreases the resonant frequency and vice versa. Length of plasma column above the ground plane increases with increasing gap ' $\mathrm{g}$ ' which in turns decreases the resonant frequency. 


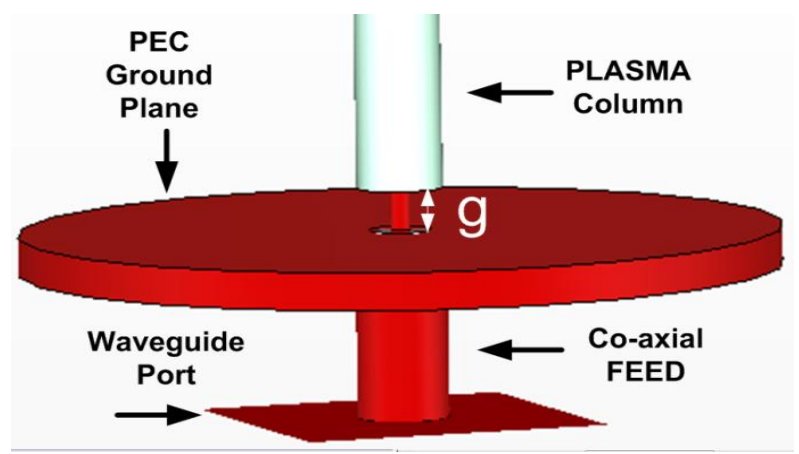

Fig 8: Plasma Antenna with gap 'g'

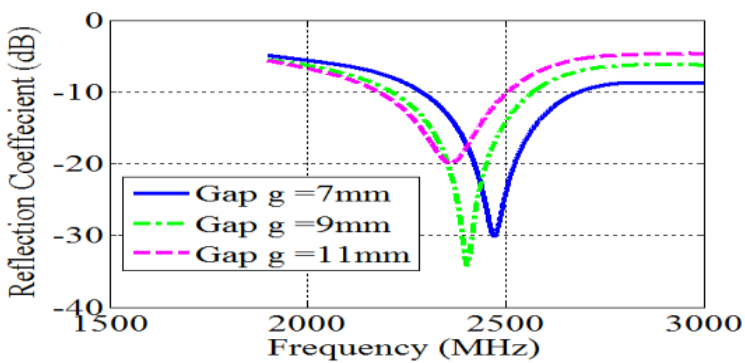

Fig 9: Bandwidth of Plasma Antenna by varying the gap ' $\mathrm{g}$ '

Table 6. Effect of varying gap between plasma column and ground plane

\begin{tabular}{|c|c|c|c|}
\hline $\begin{array}{c}\text { Gap 'g' } \\
\mathbf{m m}\end{array}$ & $\begin{array}{c}\text { Resonant } \\
\text { Freq. (GHz) }\end{array}$ & $\begin{array}{c}\text { Fractional } \\
\text { BW (\%) }\end{array}$ & $\begin{array}{c}\text { Insertion Loss } \\
(\mathbf{d B})\end{array}$ \\
\hline $\mathbf{7}$ & 24.72 & 15.53 & -30.058 \\
\hline $\mathbf{9}$ & 24 & 14.7 & -32.23 \\
\hline $\mathbf{1 1}$ & 23.64 & 9.13 & -19.93 \\
\hline
\end{tabular}

It can be seen in Table- 6 that increasing the gap decreases the bandwidth while increasing the insertion loss. To get optimized results, keep the gap at medium value such that ' $\mathrm{g}=9 \mathrm{~mm}$ '.

\subsection{Varying Radius ' $r$ ' of Plasma Column}

The relation between Radius of plasma column and resonant frequency is inversely proportional. By increasing the radius, resonant frequency shift to the lower values and vice versa as shown in Figure-10. However, the bandwidth increase by increasing the radius of monopole plasma antenna as can be seen in Table-7.

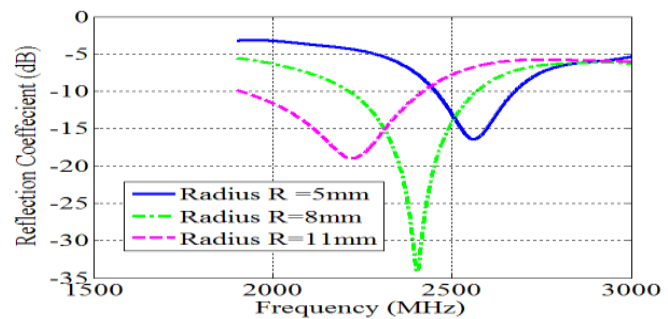

Fig 10: Bandwidth of Plasma Antenna by varying the Radius ' $r$ '
Table 7. Effect of varying Radius ' $r$ ' of Plasma Column

\begin{tabular}{|c|c|c|c|}
\hline $\begin{array}{c}\text { Radius 'r' } \\
\mathbf{m m}\end{array}$ & $\begin{array}{c}\text { Resonant } \\
\text { Freq. (GHz) }\end{array}$ & $\begin{array}{c}\text { Fractional } \\
\text { BW (\%) }\end{array}$ & $\begin{array}{c}\text { Insertion } \\
\text { Loss (dB) }\end{array}$ \\
\hline $\mathbf{5}$ & 25.85 & 8.6 & -16.419 \\
\hline $\mathbf{8}$ & 24 & 14.7 & -32.23 \\
\hline $\mathbf{1 1}$ & 23.16 & 23.166 & -19.02 \\
\hline
\end{tabular}

\section{PROPOSED PLASMA ANTENNA WITH ENHANCED BANDWIDTH}

After processing of several parametric simulations, it has come to know that bandwidth of Plasma Antenna can be enhanced by selecting proper geometric parameters. It can be seen from Figure-10 that the lowest frequency at $-10 \mathrm{~dB}$ level is $2402.4 \mathrm{MHz}$ while the highest at $4321.8 \mathrm{MHz}$.

Using the formula to find the fractional bandwidth while taking the center frequency as $\{(2402.4+4321.8) / 2\}=$ $3.362 \mathrm{GHz}$. This lead to fractional bandwidth as (4321.8$2402.4) / 3357.6=\mathbf{5 7 . 0 9 \%}$ at resonant frequency of 3.362 GHz. This makes our proposed monopole plasma antenna as broadband antenna by enhancing the bandwidth from $14.7 \%$ to $57.09 \%$.

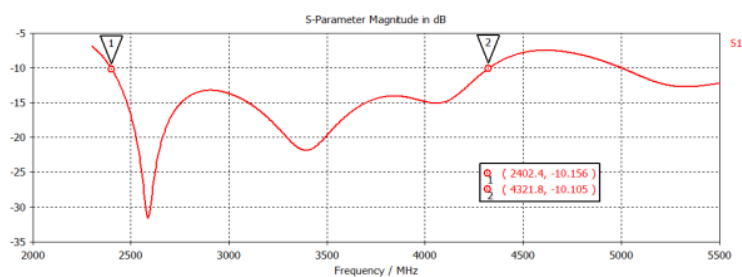

Fig 11: Impedance Bandwidth of proposed monopole Plasma Antenna

Table 8. Geometric parameters of proposed monopole Plasma Antenna

\begin{tabular}{|l|c|}
\hline \multicolumn{1}{|c|}{ Parameters } & Value \\
\hline Coax-outer & $12 / 2$. \\
\hline Glass Thickness & 0.5 \\
\hline Length & 71.3 \\
\hline Pin_insert & 12 \\
\hline Pin_Rad & 2 \\
\hline Plate Thickness & 8 \\
\hline T-C2 & 3 \\
\hline Gap & 5 \\
\hline rp & 8 \\
\hline
\end{tabular}

Where $\mathbf{r p}$ is the radius of monopole plasma antenna in $\mathrm{mm}$, $\mathbf{L}$ is the length;T_C2 is the thickness of glass in $\mathbf{m m}$, while all other parameters in table- 8 are in $\mathrm{mm}$ units.

\section{CONCLUSION}

Plasma antenna has many enhanced features than that of traditional Metal Antenna as proved in simulation results. Switching qualities of Plasma Antenna in microsecond make it possible to use in reconfigurable antenna arrays allowing the wider range of beam steering angle with shifting of phase in microsecond. 
Plasma antenna has enhanced fractional bandwidth which is $14.6 \%$ and $34.13 \%$ in case of Plasma Antenna while $10.74 \%$ and $24.93 \%$ in case of Metal Antenna at $2.4 \mathrm{GHZ} \& 1 \mathrm{GHz}$ respectively.Plasma Antenna has higher directivity which is $4 \mathrm{dBi}$ and $2.02 \mathrm{dBi}$ in case of Plasma Antenna while $3.8 \mathrm{dBi}$ and $1.31 \mathrm{dBi}$ in case of metal antenna at $2.4 \mathrm{GHZ}$ and $1 \mathrm{GHz}$ respectively.

Plasma Antenna has higher gain which is $3.5 \mathrm{~dB}$ and $6.6 \mathrm{~dB}$ in case of Plasma Antenna while $3.1 \mathrm{~dB}$ and $3.19 \mathrm{~dB}$ in case of metal antenna at $2.4 \mathrm{GHZ}$ and $1 \mathrm{GHz}$ respectively.Plasma Antenna has higher radiation efficiency which is $4.55 \mathrm{~dB}$ in case of Plasma Antenna while $1.87 \mathrm{~dB}$ in case of Metal Antenna at $1 \mathrm{GHz}$.VSWR of plasma antenna is far better than that of metal antenna such that matching of plasma antenna can be achieved easily at cost of minute design changes. Value of VSWR of Plasma antenna is 1.0397 which is much closer value to the matched VSWR which is 1 while VSWR of monopole Metal antenna is 1.3898 at resonant frequency of $2.4 \mathrm{GHz}$ which is far away from 1 the matched value of VSWR.

After parametric studies in detail, it can be concluded that wider circular ground plane with greater radius can improve the directivity and gain as well. Increasing the thickness of ground plane can improve the bandwidth but will restrict the applications where curved shapes are required. Increasing the Radius of monopole plasma antenna can also improve the bandwidth but will increase the insertion loss and other radiation losses. The gap of plasma column has inverse relation with that of frequency as the length of monopole has direct relation with gap. Increasing the gap will reduce the bandwidth but increase the insertion loss. Hence medium value is used after trade-off between bandwidth and insertion loss.

\section{RECOMMENDATIONS FOR FUTURE WORK}

In this work, monopole plasma antenna has been analyzed on the basis of bandwidth, directivity, gain, VSWR, power losses and power density and compared with monopole Metal antenna as well. After all the analyses and comparisons, it is found that the results of Plasma Antenna are improved and optimum.

Following are the recommendations for future work

- Fabrication of proposed monopole plasma antenna at different resonant frequency available at Labs.

- Dipole, Yagi-Uda and others types of antenna can be simulated by replacing metal as plasma.

- These antennas can later be fabrication and could give many interesting results.

- Further optimization techniques could be applied on proposed monopole plasma antenna to improve its bandwidth, directivity, gain, VSWR, power losses, power density and other parameters.

\section{ACKNOWLEDGMENTS}

With immense pleasure in articulating propounded regards to vulnerable and highly esteemed guide Dr. Kashif Azim Janjua and project coordinator Mr. Mukhtiar who guided with his valuable, experienced and technical knowledge in research and development as well. Special thank to Dr. Shahzada Alamgir who always willing to help and give their best suggestions during entire the period of MS degree and paper writing.

\section{REFERENCES}

[1] Fundamentals of Statistical and Thermal Physics, F. Reif, McGraw-Hill, 1965, Section 15. 16, pp 587-589.

[2] T.S. Bird, "Definition and Misuse of Return Loss," Antenna and Propagation Magazine, April 2009.

[3] T. Anderson, "Plasma Antennas", Haleakala Research and Development, Inc., (2011).

[4] V. Kumar, M. Mishra, and N. K. Joshi, "Study of a fluorescent tube as plasma antenna" Progress In Electromagnetic Research Letters, Vol. 24, 17-26, (2011).

[5] M. Lieberman and A. Lichtenberg, Principles of Plasma Discharges and Materials Processing, John Wiley \& Sons, Inc., (2005)

[6] H.M.Zali, M.T.Ali, N.A Halili and others, "Study of Monopole Plasma Antenna using Fluorescent tube in wireless Transmission experiments" $1^{\text {st }}$ IEEE symposium on Telecommunications tech, (2012).

[7] H. Jaafar, M.T.Ali, N.A Halili and others, "Analysis and Design between Plasma Antenna and Monopole Antenna", $1^{\text {st }}$ IEEE symposium on Telecomm tech, (2012).

[8] Lv, Junwei, Yingsong Li, and Zili Chen. "A SelfConsistent Model on Cylindrical Monopole Plasma Antenna Excited by Surface Wave Based on the Maxwell-Boltzmann Equation", Journal of Electromagnetic Analysis and Application, 2011.

[9] Gonano, C.A.; Zich, R.E., Antennas and Propagation (EuCAP), $20148^{\text {th }}$ European confirence on year:2014 pages 1518-1521, D01:10.1109/EuCAP.2014.6902071 IEEE conference.

[10] Zili Chen, Anshi Zhu and JunweiLv, "ThreeDimensional Model of Cylindrical Monopole Plasma Antenna Driven by Surface Wave", WSEAS TRANSACTIONS on COMMUNICATIONS, Issue 2 , Volume 12, February 2013.

[11] Ye, Huan Qing, Min Gao, and Chang Jian Tang. "Radiation Theory of the Plasma Antenna", IEEE Transactions on Antennas and Propagation, 2011.

[12] X. P. Wu, J.-M. Shi, Z. S. Chen, and B. Xu, "A new plasma antenna of beam-forming" Progress in Electromagnetic Research, Vol. 126, 539-553, (2012). 